\title{
Packaging Tank
}

National Cancer Institute

\section{Source}

National Cancer Institute. Packaging Tank. NCI Thesaurus. Code C43206.

A large receptacle used for holding, transporting, or storing liquids or gases, and often referred to as a reservoir. 